\title{
Severe Storm Clouds as Seen from TIROS
}

\author{
Linwood F. Whitney, JR. \\ U.S. Weather Bureau \\ (Manuscript received 13 November 1962, in revised form 19 March 1963)
}

\begin{abstract}
Comparisons of TIROS-viewed severe storm clouds are made with radar, sferics, and surface cloud and weather observations. Where available, the radar and sferics observations show an excellent correlation with the storm-producing cloud systems. As expected, the clouds are found to be larger than the radar echoes whereas the reliable sferics fixes closely outlined the cloud area. In the cases investigated, the cloud patterns producing severe weather are conspicuous and distinctive. They are medium scale neph systems characterized by strong brightness and well defined borders and are either isolated from other clouds or separated by a break in the cloudiness at the periphery.
\end{abstract}

\section{Introduction}

The TIROS meteorological satellites have proven to be useful and effective tools in the observation and study of large scale weather patterns. Relatively little exploration has been made into the potential utility of satellites in the observation and study of small scale weather phenomena, particularly severe local storms. Yet, the satellite affords an unprecedented opportunity to view instantaneously an entire severe weather cloud system and its environment. If the associated cloud pattern can be identified, then useful interpretations might be drawn from the photographs which would supplement investigations of severe storms. The appearance of severe storm clouds in TIROS photographs has been discussed in two cases (Whitney and Fritz, 1961, and Whitney, 1961). It is the purpose of this paper to present additional examples showing that the clouds display identifying characteristics.

An important consideration in the identification of these clouds is the resolution of the TIROS camera system. Convective clouds have appeared frequently in the photographs. Since severe local storms are convective in origin, one might expect the associated clouds to be seen. Also an outbreak of severe weather frequently occurs with a family of closely grouped convective clouds which should cause the cloud pattern to be more easily resolved by a television camera.

Erickson and Hubert ${ }^{1}$ have discussed the problem of resolution versus cumuliform cloud recognition. They found that while convective clouds appear frequently in the TIROS pictures, not all are resolved. A uniform field of scattered-to-broken small cumulus will appear, at best, as a white haze. Resolved cumulus, on the other

${ }^{1}$ Erickson, Carol O, and Lester F. Hubert, 1961 : Identification of cloudforms from TIROS I pictures. Meteorological Satellite Laboratory Rept. No. 7. Washington, U. S. Weather Bureau, 68 pp. hand, may be either a very large cumulonimbus or closely grouped aggregates of cumulus clouds. These appear in a wide spectrum of sizes within the mesoscale range but are distinctly cumuliform, having strong brightness and well defined boundaries.

In Fig. 1, after Erickson and Hubert, cumuliform clouds appear in the wide-angle picture from Kentucky northeastward into Pennsylvania. Progressively larger elements or patches of cumuliform clouds are noted northeastward from Kentucky. Two narrow-angle pictures at the left of Fig. 1 show the detail not resolved within the small dashed squares in the wide-angle picture.

The TIROS wide-angle cameras resolve only large cumulus or cumulus aggregates. Since severe weather systems producing family type outbreaks are also composed of cumulus aggregates, identification of these storm clouds is largely a problem of distinguishing them from other cumulus cloud fields.

In the following discussion, the relationship of the pictured cloud patterns to surface observations of radar, sferics, convective clouds, and severe weather will be established. Then the distinguishing characteristics which rendered the clouds conspicuous and different from other convective clouds are set forth.

\section{Discussion of pictures and relation to conven- tional analyses}

27 May 1960. Fig. 2 depicts three cloud masses situated in Kansas, Oklahoma, and Texas during the late afternoon (1719 CST) of 27 May 1960. Each cloud is detached from the vast cloudy area to the west and each is almost completely surrounded by cloudless areas, accentuating the intense brightness. The clouds measure between 120 and 180 miles in both length and breadth. This massive appearance renders them considerably 


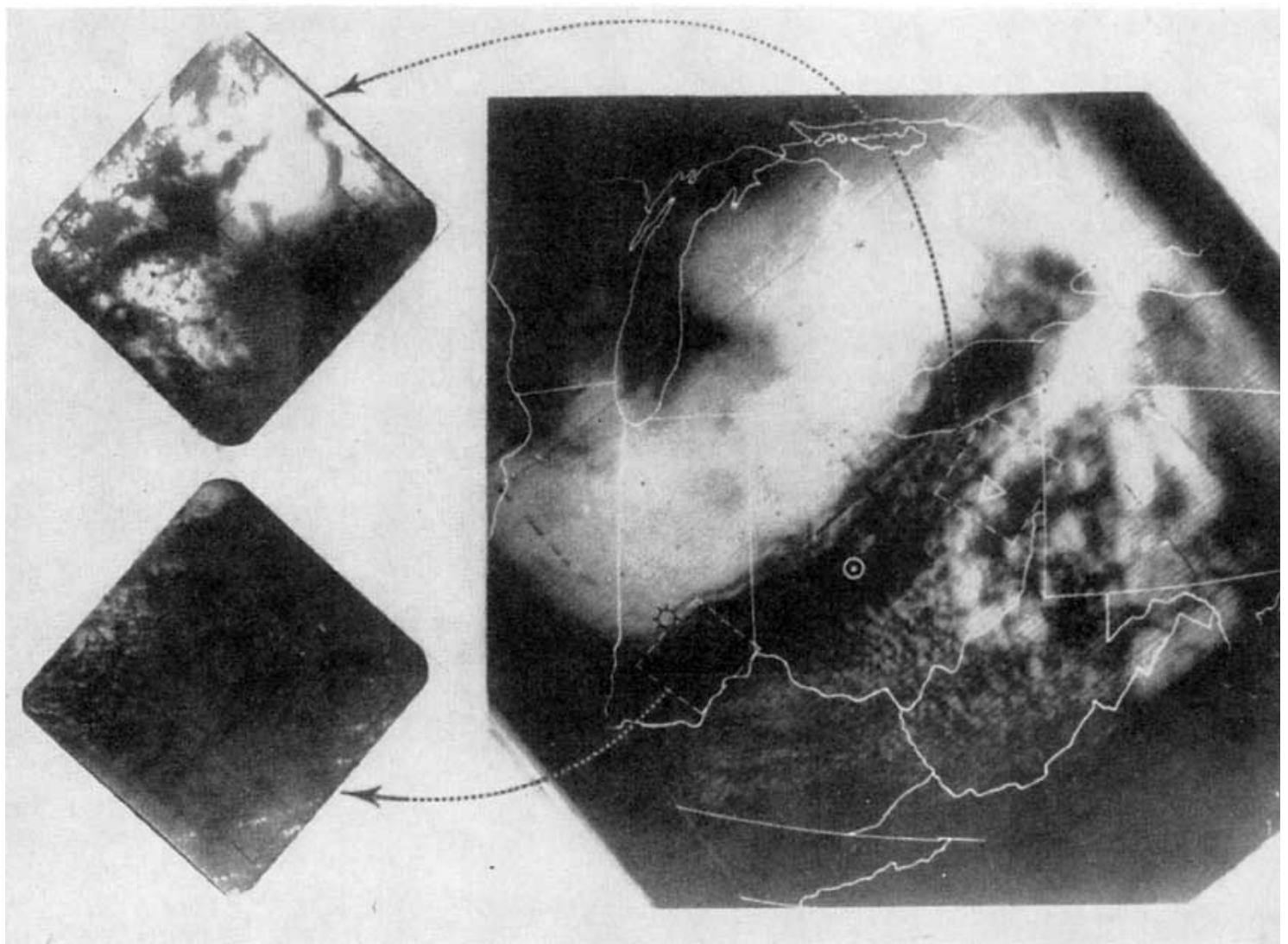

FIg. 1. TIROS I photographs taken on orbit 673 at 1505 EST, 17 May 1960. At the right is a wide-angle photograph which shows cumuliform cloud conglomerates of many sizes extending from Kentucky northeastward into Pennsylvania. At the left are narrow-angle pictures showing the detail not resolved within the small squares on the wide-angle pictures. The small triangle, the dotted circle, and the black circle with short radial lines represent, respectively, the satellite subpoint, the principal point, and the point at which specular reflection would occur if any was present.

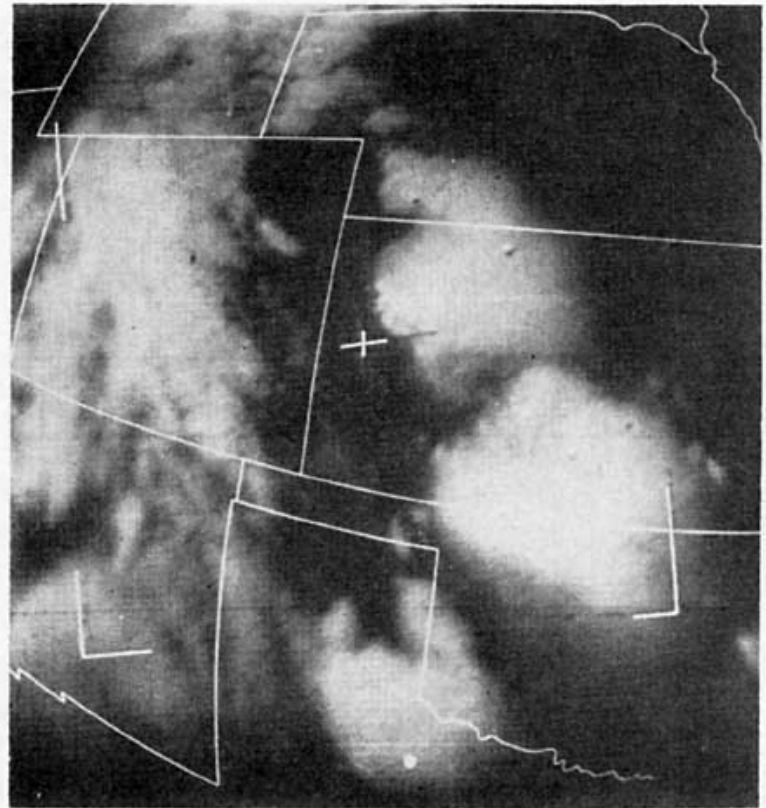

Frg. 2. TIROS I photograph taken on orbit 820 at $1719 \mathrm{CST}$, 27 May 1960. Three hail-producing cloud masses are shown covering portions of Nebraska, Kansas, Oklahoma and Texas. See Fig. 4. more prominent than the small cumulus elements nearby.

Although the brightness is very uniform, some interesting variations are evident at the borders. The variations are useful in interpreting the clouds particularly the two northernmost ones. The western sides are scalloped but sharply delineated. Some brighter spots also appear there. These observations and the over-all intense brightness suggest the clouds were primarily cumuliform in nature.

Along the eastern and southern sides, the brightness decreases gradually causing the border to be ill-defined. This suggests that cirriform clouds were streaming out from the cloud mass in response to west or northwest winds.

If then the clouds are cumuliform their large size indicates that each was comprised of many heavy cumulus and cumulonimbus clouds united by spreading cirrus anvils and other convective cloud debris.

Fig. 3 shows the radar, sferics, and TIROS observations in composite. Strong radar echoes were observed at picture time from Schilling Air Force Base, Kans., Wichita, Kans., and Wichita Falls, Tex. All echoes were confined within the bounds of, but were smaller than 
the cloud masses seen in Fig. 2. Most of the echo area was concentrated in three regions, one within each cloud. The elongated shape of the two larger echo areas suggested a line or band structure like that associated with a squall line. The large size was likely a result of the $3.2 \mathrm{~cm}$ CPS-9 radar set used at Schilling since the Wichita $10 \mathrm{~cm}$ WSR-3 set recorded a line of much smaller echoes within and along the western side of the large echo in south central Kansas. Though relatively smaller, the echoes to the southeast of the Texas Panhandle were as strong. The smaller size might well be attributed to the $10 \mathrm{~cm}$ WSR-1 radar used at Wichita Falls, Tex. Blackmer (1961) has discussed the radar analysis of this case in more detail.

Slightly larger areas were covered by the $50-\mathrm{kc}$ sferics observations. They showed a very striking correlation with the positions of the two northernmost clouds and the associated radar echoes. The sferics and the character of the radar echoes attest to the convective nature of the cloud masses.

No 50-kc sferics were noted in the Panhandle at picture time though an hour earlier the $10-\mathrm{kc}$ sferics saturated the area. Project Tornado-Sferics 1960 (U. S. Air Weather Service ${ }^{2}$ ) found severe weather (tornadoes and hail) correlated better with 50 -kc fixes than $10-\mathrm{kc}$ fixes; however, the study noted that the relation of severe weather to either was not outstanding nor did the presence of $50-\mathrm{kc}$ sferics necessarily indicate severe weather.

Discussion of the sferics area in eastern Oklahoma and northwestern Arkansas has purposely been avoided since the area is not covered in Fig. 2, and since the author was unable to locate radar photography covering the area.

The convective clouds indicated in Fig. 4, were those observed at 1700 CST. Observations of cumulonimbus or developing cumulus clouds were numerous, and several thunderstorms and showers were noted at the location of the three mesoscale cloud masses. Numerous hail storms broke out in western and southern Kansas, northwestern Oklahoma and the Texas Panhandle area during the afternoon and evening (U. S. Weather Bureau, see footnote 2). Crop damage was extensive within the area of Kansas and Oklahoma outlined in Fig. 4. Some areas reported hailstones as large as baseballs. A funnel cloud developed in northwestern Oklahoma, less than one hour after picture time. Hail up to $1 \frac{3}{4}$ inches in diameter fell in Texas just prior to picture time, and eventually, convection emanating from the Panhandle area produced a tornado in central Oklahoma. There can be little doubt that the cloud masses shown in Fig. 2 were associated with the severe weather.

Another interesting aspect arising from the conventional data was that the west to northwest winds above

${ }^{2}$ U. S. Air Weather Service, Department of the Air Force, 1960: Project tornado-sferics 1960. Prepared by Detachment 4 (Severe Weather Warning Facility), 4th Weather Group, Air Weather Service (MATS), 22 pp.
$10,000 \mathrm{ft}$ over the storm area support the contention that cirrus clouds streamed out on the south and east side of the cloud masses.

28 May 1960 . On the following day, 28 May, at 1627 CST, TIROS I again photographed a bright cloud mass in central Kansas and northern Oklahoma (see Fig. 5). This mass while not isolated, as were those in Fig. 2, is prominent because of the brightness, the break in cloudiness around its periphery, and the adjacent dark area to the east.

The locations of the radar and sferics observations (see Fig. 6) coincide with that of the bright cloud mass.

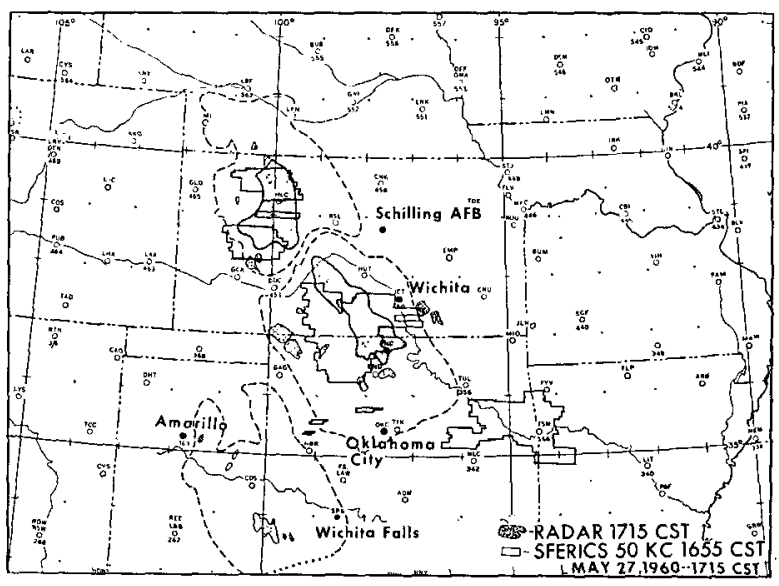

FIG. 3. Radar and sferics observations for times near that of Fig. 2. The radar echoes are shaded; sferics observations are outlined and were obtained using four station fixes. The dashed lines represent the outline of the clouds in Fig. 2 associated with severe storms.

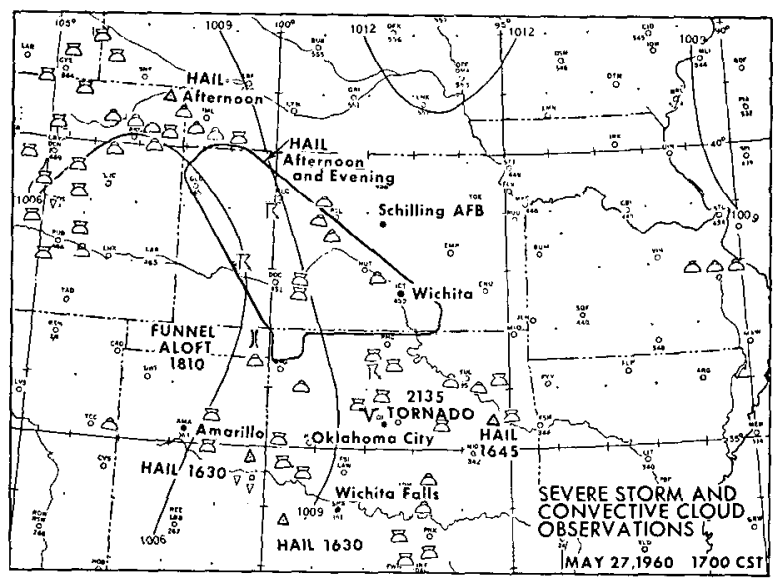

FIG. 4. Convective cloud and thunder storm observations made at $1700 \mathrm{CST}$ and severe storm occurrences noted during the afternoon and evening of 27 May 1960. Within the region outlined in Kansas and Oklahoma many local areas reported severe hail damage. Hailstones ranged from $\frac{3}{4}$ inches in diameter to baseball size. Smaller stones up to $1 \frac{3}{4}$ inches diameter fell in the Texas storms. In this figure as in Figs. 7 and 9, cloud symbols have been located by reported directions, but they are not necessarily at the correct distances since none were reported. 


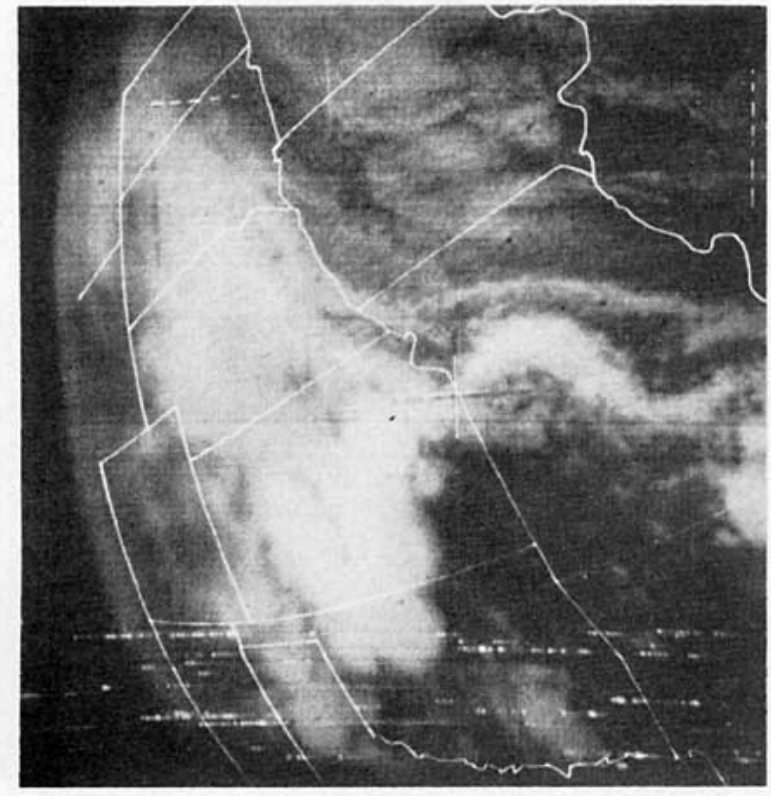

Fig. 5. TIROS I photograph taken on orbit 834 at 1627 CST, 28 May 1960 . The bright mesoscale cloud in central Kansas and northwestern Oklahoma produced hail and one tornado. The less prominent clouds in the Texas Panhandle northward into southeastern Colorado were associated with tornadoes, funnels aloft and hail. See Fig. 7 .

Echoes from the Wichita radar scope are shown. No radar photography was available from Schilling Air Force Base for this case. As usual, the radar echoes were smaller than the cloud mass whereas the sferics observations bore a striking resemblance to the size and shape of the cloud.

Severe thunderstorms brought hail, heavy rains, electrical damage and high winds to southern Kansas and northwestern Oklahoma (U. S. Weather Bureau, 1960). One tornado struck in the open country of northwestern Oklahoma. Many local areas within the region. outlined in Fig. 7 were affected over a two hour period which included the picture time. Hailstones were from 1 inch in diameter to baseball size. In one hail area winds reached $60 \mathrm{mph}$ while heavy showers produced 1 to 4 inches of rainfall at other locations. As a result of these storms, crop damage was severe, and in some instances, complete. These severe storms were associated with the southern portion of the mesoscale bright cloud mass appearing in Fig. 5.

Four short-lived tornadoes and three funnels aloft developed in the Texas Panhandle (U. S. Weather Bureau, 1960) near picture time while $\frac{1}{4}$ to $\frac{1}{2}$ inch hail accumulated to a depth of 3 inches in Lamar County, Colorado. The clouds seen in these areas (see Fig. 5) are not as prominent as severe storm clouds seen in this and other TIROS photographs nor were sferics fixes recorded there. While the clouds are mesoscale and somewhat isolated or surrounded by breaks in the cloud cover, they appear diffuse and lack the intense bright-

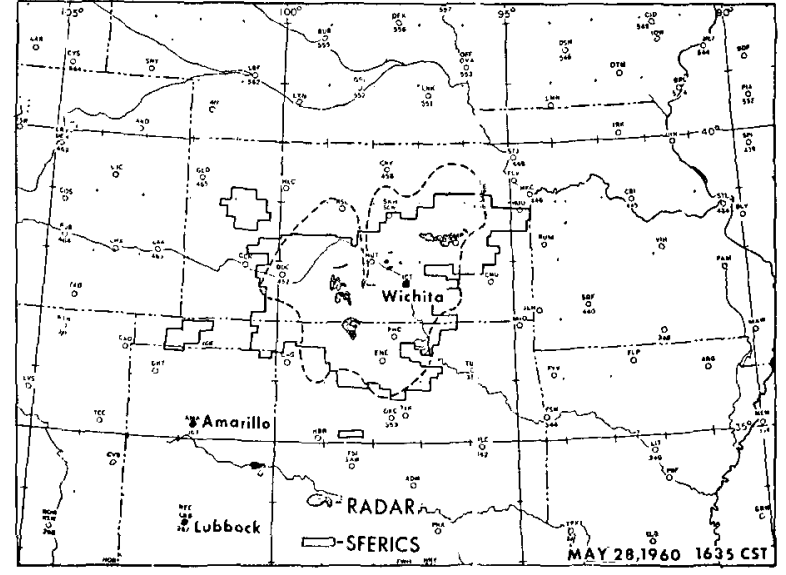

Fig. 6. Radar and sferics observations on 28 May 1960 near the time of Fig. 5. The radar echoes are shaded. Sferics observations are outlined and were obtained using, $\mathrm{f}$ frequency of $10 \mathrm{kc}$. The number of stations used to make the sferics fixes is unknown. A dashed line represents the outline of the major cloud system in Fig. 5 associated with severe weather.

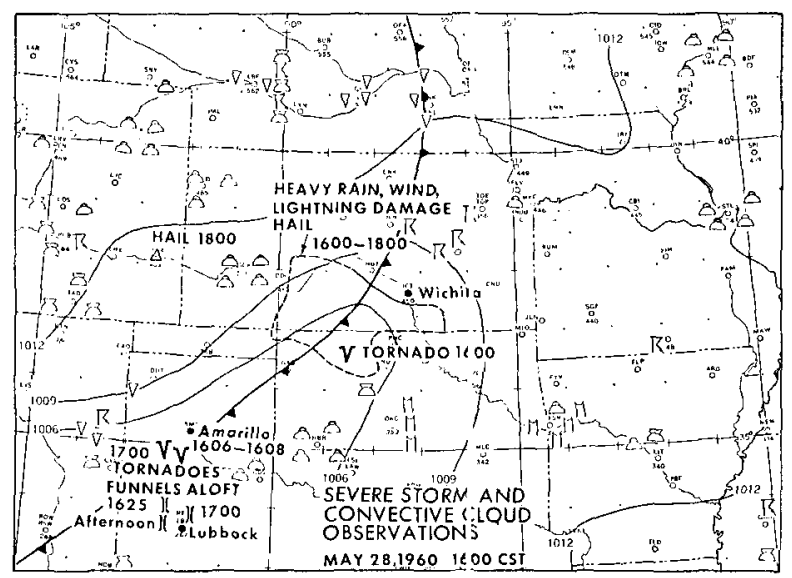

FIG. 7. Severe local storm and convertive cloud for 28 May 1960 near the time of Fig. 5. The times and types of severe weather are indicated; all convective cloud observations were made at 1600 CST. The hailstones ranged from 1 in $:$ h diameter to baseball size in Kansas and Oklahoma. One to foul inches of rain fell in some areas while winds reached speeds as high as $60 \mathrm{mph}$. In Colorado $\frac{1}{4}$ to $\frac{1}{2}$ inch hail accumulated to a depth of three inches.

ness seen in other storm clouds. Such inconsistencies must presently be expected sinc: so many factors affect the appearance and brightness of cloud images. The clouds in the Panhandle, for i.nstance, are in a poor focus region of the picture formal. (Erickson and Hubert, 1961) and being near the horizon are poorly resolved. These factors together with the obvious noise at the bottom of Fig. 5 contribute to the diffuse appearance.

The brightness in any satellite photograph may be influenced by many factors (Gla ser and Conover, 1957; Erickson and Hubert, see footnote 1). For instance, the brightness may be uneven because of sun angle, viewing angle, or optical characteristics Erickson and Hubert 
have found a tendency in some TIROS photographs for the brightness to be greater along the "sun path," i.e., objects in the direction of the sun appeared brighter. Also the illumination of any photograph may be expected to be greatest at the center of the field (American Society of Photogrammetry, 1952) and progressively decrease toward the edges. To what extent this latter factor influences TIROS I photographs is uncertain; however, the test target televised through the system (Staff Members, Radio Coropration of America, ${ }^{3}$ ) prior to launch does show a decrease in brightness toward the edges. Both of these factors probably influenced the appearance of the clouds in the Texas Panhandle, particularly the latter since the clouds appeared near the edge of the picture.

Alteration of brightness may also occur with monitor adjustments at the readout sites, in the original film exposure, and later in paper prints by the photographer's exposure. All of the above factors when coupled with lack of brightness calibration with each photograph have frustrated efforts to quantitatively measure brightness. The meteorologist then in studying a TIROS photograph is forced to consider brightness qualitatively and so must keep in mind those factors which may affect his interpretations.

Many of the cloud formations depicted in Fig. 5 were also associated with convective clouds or thunderstorms. These clouds lacked some characteristics which have been associated with severe storm clouds. For instance, the bright clouds in Nebraska were associated with showers and thunderstorms, but the clouds had a mottled appearance and were a part of a large-scale cloud system extending northward into Canada. The latter characteristics are contrary to the medium scale and uniform appearance of the severe storm clouds noted thus far.

While the bright, sharply defined clouds shown in southeastern Arkansas (see Fig. 5) were associated with thunderstorms (see Fig. 7), they are quite small (less than 60 miles in diameter) as compared with the medium scale well organized cloud system shown in central Kansas or the clouds in the Texas Panhandle. Still an area of concentrated local convection is indicated, and the clouds would be suspect because of possible intensification. To date the few cases of satellite-viewed severe storm clouds investigated have been those which were already well developed and either were producing or were about to produce, severe weather.

30 May 1960. A prominent band of clouds which was photographed at mid-afternoon is seen in Fig. 8 extending about 200 miles from northern Virginia to western North Carolina. Another prominent cloud system is also seen in eastern portions of North Carolina. Both cloud

${ }^{3}$ Staff Members, Radio Corporation of America, 1960: Sensor and calibration data for TIROS I, Vehicle D-3. Astro-Electronic Products Division, Princeton, N. J., 19 pp. patterns are bright, appear distinctly cumuliform and are surrounded by relatively clear skies. Both are medium scale features.

The long, narrow cloud line in Virginia, however, is not quite of the same appearance as the severe storm clouds noted to date. It is not approximately of equal dimensions in all horizontal directions, i.e., it does not appear as a massive homogeneous unit. Nevertheless, eastern portions of Virgina were struck by severe storms later in the day (Fig. 9). Hailstones up to one inch in diameter damaged crops and windows. Three-inch stones fell northeast of Richmond. Numerous trees were downed by high winds accompanying the hail storms and flash flooding was reported in one county. In Maryland, a waterspout caused minor damage along the Potomac shore 30 miles south of Washington, D. C.

Crop damage by hail (see Fig. 9) was widespread in five counties of eastern North Carolina in association with clouds depicted there in Fig. 8. The hail began shortly before picture time and continued for three hours.

Little information was added in this case by the radar and sferics (see Fig. 10) observations. The Cape Hatteras radarscope did reveal numerous echo cells associated with convection in North Carolina, but no photographs were available for central Virginia. Most of the sferics fixes were probably spurious since they were obtained using only three-station fixes, and being remote from the network, the bearing lines intersected at small angles producing elongated fix areas (U. S. Air Weather Service, 1960). As might be expected, the fixes bore little resemblance to the cloud patterns.

24 May 1960. TIROS photographs taken on this date demonstrate the potential capability of both recognizing and tracking severe weather systems with satellites. Normally the TIROS satellites view a given area once daily, the interval between successive passes being longer than the life of most severe weather systems. Only when at high latitudes near the orbit inversion and when the cameras are at a favorable viewing angle, can TIROS duplicate coverage on successive orbits.

On 24 May 1960, TIROS I viewed the same severe storm clouds on three successive passes. The photograph taken on the first of these orbits was of poor quality and is not shown here. The pictures from the two succeeding orbits are shown in Figs. 11 and 12. Each shows a bright, uniform cloud mass in eastern Iowa. As in the pictures discussed earlier, dark areas may be seen adjacent to the bright cloud mass. From surface observations it was apparent that numerous thunderstorms were embedded in the cloud pattern. Funnel clouds materialized in eastern Iowa about 45 minutes prior to the time of Fig. 11. Later, after Fig. 12 was photographed, severe thunderstorms produced high winds, heavy rains, and hail in central Illinois. Examination of Figs. 11 and 12 reveals the translation or development of the cloud pattern toward the southeast into Illinois. 


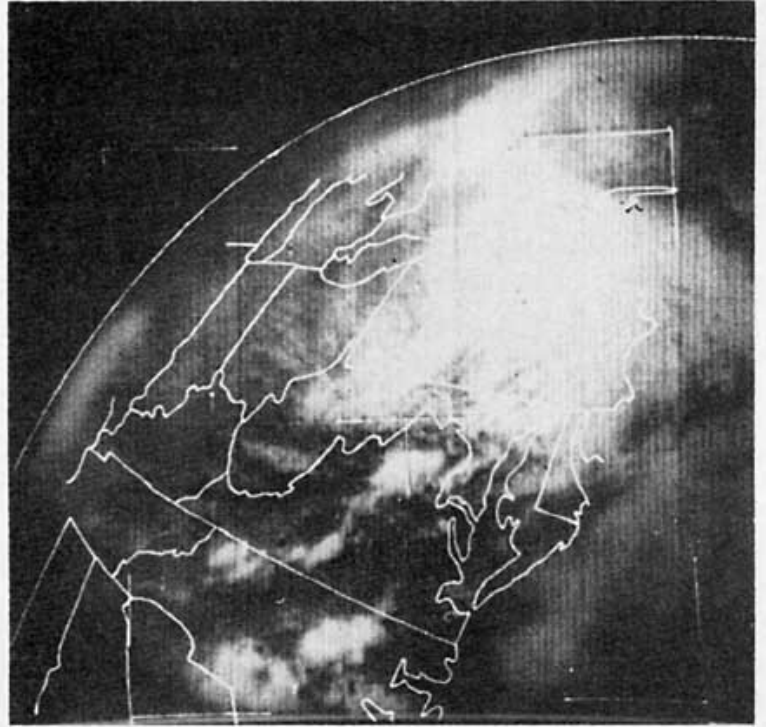

FIG. 8. TIROS I photograph taken on orbit 862 at 1544 EST, 30 May 1960. Those cloud masses seen in central Virginia and eastern North Carolina produced severe local storms. See Fig. 9.

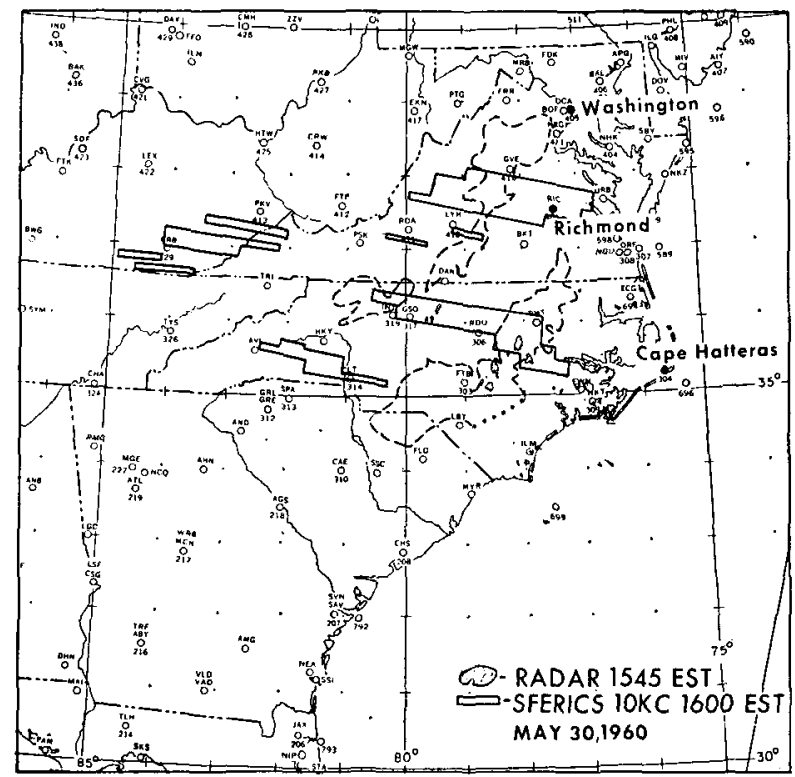

Frg. 10. Radar and sferics observations for 30 May 1960 near the time of Fig. 8. The radar echoes are shaded; sferics observations are outlined and were obtained using three-station fixes. Those areas outlined by dashed lines are the boundaries of clouds in Fig. 9 associated with severe weather.

\section{Summary and conclusions}

These photographs show that prominent cloud patterns producing locally severe weather exhibited some common characteristics. They were distinguished from other cumulus cloud patterns by the medium scale size and the unbroken, uniform appearance. Each was either separated or completely isolated from other cloud cover. All were in the large-size range of the mesoscale spectrum, measuring between 100-200 miles in length. Being

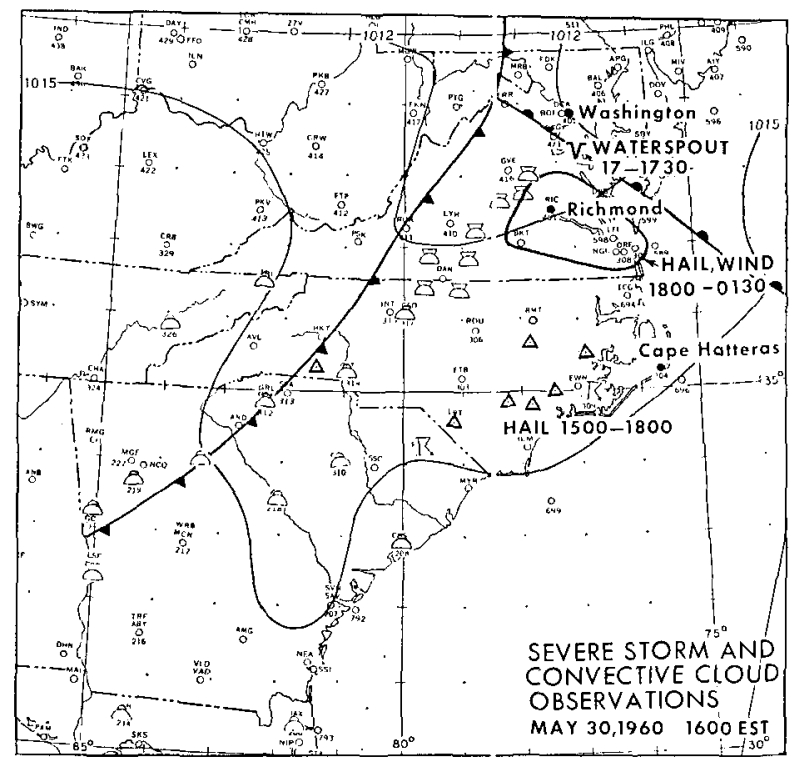

Fig. 9. Severe local storm and conv sctive cloud observations for 30 May 1960, near the time of Fis;. 8. The times of severe weather are indicated; all convective cloud observations were made at 1600 CST. The hail caused widespread crop damage. Most hailstones were less than 1 inch in diameter, but some of baseball size fell northeast of Richmond. High winds felled many trees in Virginia. The waterspout causer only minor damage.

usually of a similar transverse dimension, they appeared as massive cloud blobs. Although each pattern was a large unit with little internal detail, the sharply defined borders, the scalloped appearance along portions of the border, and the overall intense b:ightness were indications of their convective nature.

One of the most distinctive characteristics noted in these and earlier cases was the massive blob appearance of the storm clouds. With one exception there was no impression of a long line of cumul as development which might be expected in cases of squall lines. Though the cloud masses appeared uniform and unbroken, the radar and surface observations stowed that the masses were not uniform either in structure or in weather produced. The radar echoes were collectively much smaller than the host cloud, a finding noted in investigations by Blackmer (1961) and Fujita and Ushijima (1961). One should naturally expect instantaneous shower areas to be smaller than the convective :loud producing them. However, the concentrated nature of the echoes, relative to the cloud size and the surface observations beneath the severe storm clouds varying from cumulus congestus to thunderstorms indicated the slouds were composed of many convective clouds in varying phases of development, but contained a concentrłted area of vigorous convection. The exception to the mass appearance of the storm clouds was the line of convective clouds in central Virginia on 30 May 1960. These clouds were in a very early stage of developmer $t$ and preceded the family outbreak of hail, wind, ard rainstorms by more than two hours. In the other cases, development had 


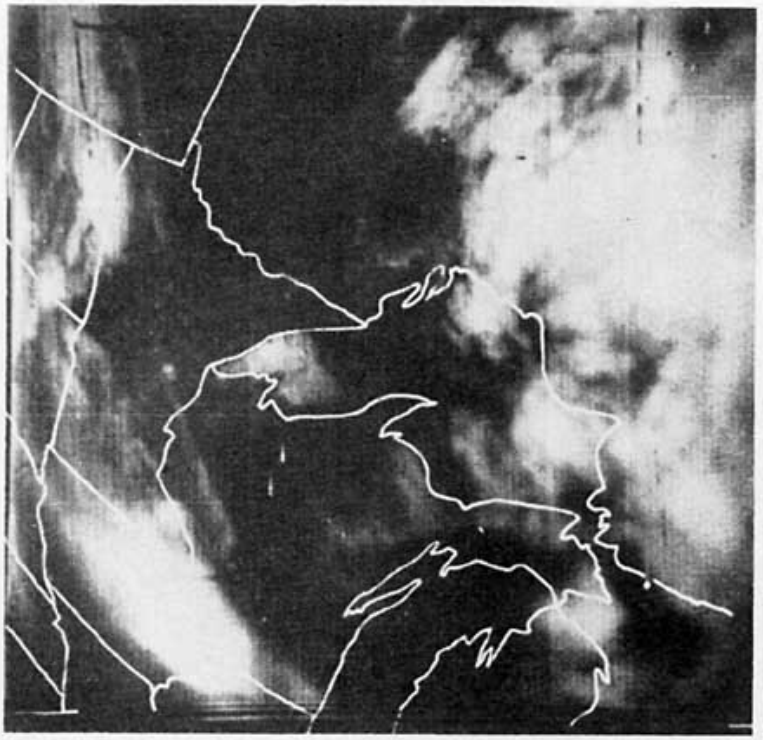

FIG. 11. TIROS I photograph from orbit 776 at 1448 CST, 24 May 1960. The bright mesoscale cloud mass in eastern Iowa produced funnels aloft just 45 minutes prior to picture time. A later position of this cloud mass may be seen in Fig. 12.

begun some time before that of the picture and the severe weather was either occurring or imminent. Regarding the age of convective clouds, Fujita ${ }^{4}$ and Fujita and Ushijima (1961) have noted the increase in size of the clouds with time because of the expanding cirrus anvils. Their findings and the TIROS photographs presented here suggest that when viewing a mature storm system the satellite sees not the many closely grouped cumulonimbus clouds in the convective area but rather sees the anvils which have united and expanded beyond the bounds of the storm area.

Sferics fixes were obtained for three of the cases reported above. The data were reliable in two cases, and an excellent correlation was established between the fix areas and the TIROS viewed storm clouds. This sort of striking correlation was observed in another case reported earlier (U. S. Air Weather Service, 1960; Whitney, 1961).

An adjunct characteristic of the severe storm cloud pattern was the contiguous clear area. The size of the area varied within wide limits. Sometimes it appeared as a hole in a large cloud layer around the storm cloud system suggesting its formation was caused by subsidence compensating for the intense convection in the storm area. Hence, the size of the adjacent clear area may be useful in determining the severity or potential severity of the storm system. At other times, the clear area was so vast, covering may thousands of square

${ }^{4}$ Fujita, Tetsuya, 1961: A review of researches on analytical mesometeorology. Mesometeor. Proj. Research Rept. No. 8, Chicago, $114 \mathrm{pp}$.

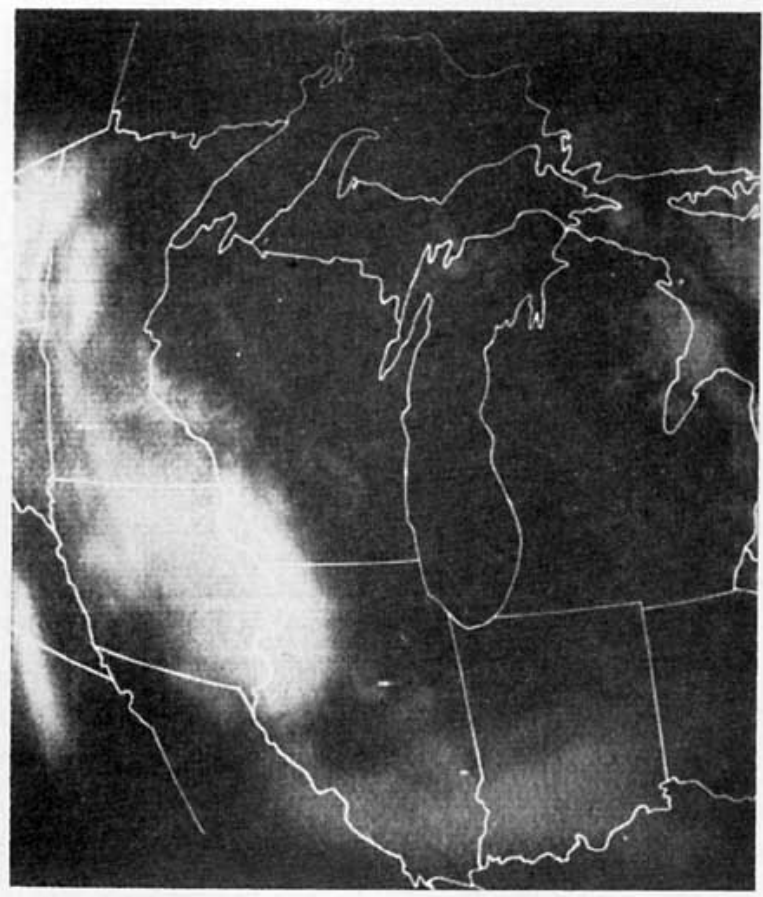

FIG. 12. TIROS I photograph taken on orbit 776 at 1633 CST, 24 May 1960. The bright cloud mass in eastern Iowa and northwestern Illinois is a later view of the severe weather cloud pattern seen in Fig. 11. Severe thunderstorms produced high winds, heavy rains, and hail in central Illinois following the time of this picture?

miles, that it must have been independent of any intense local convection.

Lastly, evidence was presented indicating the potential of tracking severe weather systems with satellites. Though this is seldom possible with TIROS series, other satellites are anticipated which will give more frequent or even continuous coverage of the earth.

\section{REFERENCES}

American Society of Photogrammetry, 1952: Manual of photogrammetry. Washington, D. C., 876 pp.

Blackmer, Roy H., Jr., 1961 : Satellite observations of squall line thunderstorms. Proc. Ninth Weather Radar Conf., Boston, Amer. Meteor. Soc., 76-82.

Fujita, Tetsuya, and Toshimitsu Ushijima, 1961: Investigation of squall lines with the use of radar and satellite photographs. Proc. Ninth Weather Radar Conf., Boston, Amer. Meteor. Soc., 186-192.

Glaser, Arnold H., and John H. Conover, 1957: Meleorological utilization of images of the earth's surface transmitted from a satellite vehicle. AFCRC-TR-57-241, ASTIA-AD-146764, Harvard University, Blue Hill Meteorological Observatory, 145 pp.

U. S. Weather Burcau, Dept, of Commerce, 1960: Storm data, 2, 46. Whitney, Linwood F., Jr., 1961: Another view from TIROS I of a severe weather situation-May 16, 1960. Mon. Wea. Rev., 89, 447-460.

-_, and Sigmund Fritz, 1961: A tornado-producing cloud pattern seen from TIROS I. Bull. Amer. meleor. Soc., 43, 603-614. 